\title{
Aplicação da fermentação em estado sólido na biotransformação do resíduo do cajá
}

\author{
Application of solid state fermentation for the \\ biotransformation of a yellow mombin by product
}

Alexsandra Nascimento Ferreira ${ }^{[a]}$, Clissiane Soares Viana Pacheco ${ }^{[b]}$, Iasnaia Maria de Carvalho Tavares ${ }^{[c]}$,

Thiago José Onório Rocha ${ }^{[\mathrm{d}]}$, Marcelo Franco ${ }^{[\mathrm{e}]}$

[a] Graduanda do curso de Química da Universidade Estadual do Sudoeste da Bahia, Itapetinga, BA - Brasil, e-mail: alexsandraquimica@hotmail.com

[b] Graduanda do curso de Química da Universidade Estadual do Sudoeste da Bahia, Itapetinga, BA - Brasil, e-mail: clissianesoares@hotmail.com

[c] Engenheira de alimentos, Mestranda do PPG em Engenharia de Alimentos da Universidade Estadual do Sudoeste da Bahia, Itapetinga, BA - Brasil, e-mail: iasnaiamct@yahoo.com.br

[d] Graduando do curso de Química da Universidade Estadual do Sudoeste da Bahia, Itapetinga, BA - Brasil, e-mail: tjor.mqf@gmail.com

[e] Químico, Doutor em Química Orgânica e professor adjunto do Departamento de Estudos Básicos e Instrumentais da Universidade Estadual do Sudoeste da Bahia, Itapetinga, BA - Brasil, e-mail: marcelofranco@pq.cnpq.br

\section{Resumo}

Este trabalho teve por objetivo verificar o efeito do tempo de fermentação $(24,48,72$ e 96 horas) e umidade (50\%, 60\% e 70\%) sobre a atividade específica da enzima endoglucanase produzida por meio da fermentação em estado sólido do resíduo de cajá sob ação do fungo Aspergillus niger. A atividade específica foi calculada pela divisão do valor da atividade enzimática, obtida por meio do método da CMCase, pelo valor de proteína bruta obtida a partir do método de Bradford. Os maiores valores de atividade específica ocorreram em 72 horas de fermentação, enquanto a maximização da produção de endoglucanase $\left(531 \mathrm{U} \cdot \mathrm{mg}^{-1}\right)$ ocorreu a 50\% de umidade. Concluiu-se que a biotransformação do resíduo de cajá sob fermentação em estado sólido é uma forma viável de obtenção da enzima endoglucanase.

Palavras-chave: Método de Bradford. Endoglucanase. Aspergillus niger.

\section{Abstract}

This research aimed to study the effect of fermentation period (24, 48, 72 and $96 \mathrm{~h}$ ) and humidity (50\%, 60\% and $70 \%)$ on endoglucanase enzyme produced during solid state fermentation of a yellow mombin byproduct under the action of the fungus Aspergillus niger. The specific activity was calculated as a ratio of CMCase enzyme activity and crude protein obtained by the Bradford method. The highest values of specific activity were detected at 72 hours of fermentation, while maximization of endoglucanase production (531 $\mathrm{U}^{\mathrm{mg}} \mathrm{g}^{-1}$ ) occurred 
at the humidity level of 50\%. In conclusion, the biotransformation of yellow mombin byproduct under solid state fermentation is a feasible way to produce endoglucanases.

Keywords: Bradford method. Endoglucanase. Aspergillus niger.

\section{Introdução}

A geração de subprodutos é inerente a qualquer setor industrial. Com o aumento da conscientização ecológica, iniciado no final do século XX, ficou claro que o grande desafio da humanidade será equilibrar a produção de bens e serviços, o crescimento econômico, a igualdade social e a sustentabilidade ambiental (PELIZER et al., 2007). A preocupação com o meio ambiente leva à viabilização de projetos que promovem a sustentabilidade do sistema de produção, ao contrário do que acontecia no passado, quando resíduos eram dispostos de forma indevida. Atualmente, os reaproveitamentos desses subprodutos são cada vez mais difundidos (LAUFENBERG et al., 2003; MANERA et al., 2011; PELIZER et al., 2007).

No Brasil, a indústria de alimentos produz grande quantidade de subprodutos. Aplicá-los em bioprocesso é viável, tendo em vista o seu baixo valor agregado, além da grande disponibilidade. Nesse sentido, as pesquisas com bioprocessos crescem exponencialmente e o foco da maioria delas é produzir compostos com alto valor agregado a partir dos subprodutos agroindustriais (COUTO; SANROMAN, 2006; SOCCOL; VANDENBERGHE, 2003). Basicamente, esses subprodutos são constituídos de compostos lignocelulósicos, os quais são os recursos renováveis mais abundantes na natureza, sendo esses constituídos majoritariamente de celulose, hemicelulose e lignina (CASTRO; PEREIRA, 2010; GALEMBECK et al., 2009).

Os compostos lignocelulósicos são os principais componentes para os bioprocessos (SANTOS et al., 2006). Dentre esses bioprocessos a fermentação no estado sólido (FES) se destaca, sendo utilizada na obtenção de diversos produtos com grande importância comercial (GALEMBECK et al., 2009; ROSSI et al., 2009). A FES pode ser definida como a deposição de micro-organismos sobre partículas sólidas com a quantidade de água suficiente para o crescimento celular. 0 processo de FES é mais eficiente quando são aplicados os fungos filamentosos (GERVAIS;
MOLIN, 2003). Os fungos do gênero Aspergillus são economicamente importantes, sendo utilizados em numerosas fermentações, incluindo a produção de ácido cítrico, além de ser o micro-organismo mais usado na produção de enzimas (ROBINSON; NIGAM, 2003; MINAFRA et al., 2010).

0 reaproveitamento de materiais lignocelulósicos é interessante do ponto de vista industrial, uma vez que a hidrólise da celulose resulta, no fim do bioprocesso, na molécula de glicose (SANTOS; GOUVEIA, 2009). A biodegradação da celulose é estimulada pelas enzimas celulolíticas, naturalmente, e as celulases livres são produzidas por fungos e bactérias aeróbicos (SALES et al., 2010; BASSO et al., 2010). Apesar das enzimas bacterianas serem mais eficientes industrialmente, as enzimas fúngicas dominam as aplicações comerciais em razão de seu alto nível de expressão e secreção.

Lee et al. (2002) destaca que, principalmente, três enzimas estão envolvidas na degradação da celulose: endoglucanase (endo-1,4- $\beta$-D-glucanase, EC 3.2.1.4), celobiohidrolase (exo-1,4- $\beta$-D-glucanase, EC 3.2.1.91) e $\beta$-glicosidase (1,4- $\beta$-D-glicosidase, EC 3.2.1.21). 0 uso dessas enzimas em processos industriais tem se demonstrado cada vez mais promissor. As enzimas celulolíticas se destacam no beneficiamento de produtos de indústrias têxteis, de papel, farmacêutica e alimentícia, dentre outras (ABDESHAHIAN et al., 2011; MALIK et al., 2010; OBEROI et al., 2010).

A produção de enzimas por fungos filamentosos é influenciada pelas condições de cultivo, em particular da umidade do meio de cultura, tipo de fonte de nutrientes, temperatura de cultivo, além de outros fatores. No Brasil, a fruticultura produz grande quantidade de subprodutos, tais como bagaços, farelos, cascas e sementes. Seu reaproveitamento como matéria-prima é viável graças ao seu baixo custo econômico e à sua elevada concentração de nutrientes, que tem potencial de uso para conversão por micro-organismos na obtenção de produtos de alto valor agregado, como enzimas (COUTO; SANROMAN, 2006; SOCCOL; VANDENBERGH, 2003). 
A industrialização do cajá gera grande quantidade de subprodutos. Essa biomassa é obtida principalmente pela produção de polpa de fruta, sendo essa uma excelente fonte nutricional para os micro-organismos. Atualmente, a polpa congelada de cajá é uma das mais apreciadas em nível nacional, e a demanda a cada dia aumenta apesar da pouca existência de plantios comerciais. Em razão de problemas de colheita, condições de acesso e transporte, são estimados que menos de $30 \%$ da produção de cajá, na região sul da Bahia e em outras regiões produtoras, seja aproveitada para o consumo humano (BRITO, 2010).

Este trabalho teve como objetivo estudar o efeito da temperatura, do tempo de fermentação e da umidade sobre a atividade cinética da endoglucanase (CMCase), produzida por meio da fermentação em estado sólido sobre o resíduo de cajá (Spondias mombin) com auxílio do fungo Aspergillus niger.

\section{Materiais e métodos}

O micro-organismo utilizado no experimento foi o fungo Aspergillus niger proveniente de uma cepa do Laboratório de Reaproveitamento de Resíduos Agroindustriais da Uesb. A esporulação da cultura fúngica foi efetuada em agar-batata-dextrose (HiMedia ${ }^{\circledR}$ acidificado inclinado), incubada a $35^{\circ} \mathrm{C}$ por sete dias em estufa bacteriológica (modelo SL 101 Solab) e suspensa em solução de Tween 80 Vetec a 0,01\%, para proceder a contagem de esporos em suspensão com auxílio da câmara de Neubauer dupla espelhada e o microscópio binocular Bioval L1000. Foram obtidos aproximadamente $30 \mathrm{~kg}$, base úmida, do resíduo de cajá de uma indústria de processamento de frutas localizada na região sudoeste da Bahia. 0 resíduo foi seco em estufa de secagem e esterilização, com circulação de ar forçada (Solab) a $70{ }^{\circ} \mathrm{C}$ por $24 \mathrm{~h}$, sendo posteriormente triturado em moinho tipo Wiley (20 mesh) e autoclavado (Solab) a $121^{\circ} \mathrm{C}$ e $1 \mathrm{~atm}$ por 15 minutos.

As fermentações foram realizadas em Erlenmeyers contendo $10 \mathrm{~g}$ de resíduo, previamente autoclavados a $121{ }^{\circ} \mathrm{C}$ por 15 minutos. Foram adicionadas diferentes quantidades de água estéril de forma a ajustar a umidade $(50 \%, 60 \%$ e $70 \%)$ em função da matéria seca. Nesses sistemas de fermentações adicionou-se uma suspensão contendo $10^{7}$ esporos por grama de substrato. As incubações foram conduzidas à temperatura constante $\left(25^{\circ} \mathrm{C}\right)$ em diferentes tempos de fermentações ( 24 h, 48 h, 72 h e 96 h) em estufa bacteriológica refrigerada (Solab modelo SL 101). Finalizado o tempo de fermentação, a cada Erlenmeyer foram adicionados $50 \mathrm{~mL}$ de solução tampão de citrato de sódio (Vetec) com pH 4,8 a 50 mM. Essa suspensão foi agitada a $150 \mathrm{rpm}$ à temperatura ambiente durante uma hora em incubadora com agitação orbitalar (Quimis modelo Q816M20). A suspensão contendo o extrato enzimático bruto foi extraída por meio da prensagem mecânica, e a solução obtida foi centrifugada a 1000 rpm por 10 min (Cetribio modelo 80-2B).

A atividade cinética da enzima endoglucanase (CMCase) foi determinada por meio da dosagem dos açúcares redutores produzidos na degradação enzimática da carboximetilcelulose (Cromoline) a $2 \%$ $\mathrm{p} / \mathrm{v}$ diluído em solução de citrato de sódio com o pH 4,8 a $50 \mathrm{mM}$ e sua quantificação ocorreu por meio do método do ácido dinitrosalicílico (DNS) (MILLER, 1959). Em três tubos de ensaio foram adicionados: a) 0,5 mL de solução tampão de citrato de sódio com o $\mathrm{pH} 4,8$ a $50 \mathrm{mM}, 0,5 \mathrm{~mL}$ de extrato enzimático bruto e $0,5 \mathrm{~mL}$ de CMC ( $2 \%$ p/v); b) controle da reação - 0,5 $\mathrm{mL}$ do mesmo tampão e $0,5 \mathrm{~mL}$ de extrato enzimático; c) branco da reação - 0,5 mL de DNS e 0,5 mL de solução tampão. Todos os tubos foram incubados em estufa bacteriológica (Quimis) a $50{ }^{\circ} \mathrm{C}$ por dez minutos. A reação foi interrompida com a adição de $0,5 \mathrm{~mL}$ DNS. Os tubos foram submergidos em banho-maria (Solab) por cinco minutos, após esse tempo foram adicionados 6,5 mL de água destilada e, posteriormente, foi efetuada a medição de absorbância em $540 \mathrm{~nm}$ no espectrofotômetro Bel Photonics 2000 UV. Essa quantificação foi repetida três vezes para cada unidade de tratamento. A unidade de atividade enzimática (U) foi definida como a quantidade de enzima capaz de liberar $1 \mu \mathrm{mol}$ de açúcares redutores por minuto a $50{ }^{\circ} \mathrm{C}$, sendo a atividade enzimática expressa em $\mathrm{U} \cdot \mathrm{mL}^{-1}$. A quantificação da proteína bruta no extrato enzimático foi efetuada por meio do método de Bradford (BRADFORD, 1976). A atividade específica da enzima foi definida como sendo a divisão do valor da atividade enzimática pelo teor de proteína bruta.

\section{Resultados}

Na Tabela 1 são apresentados os resultados obtidos para as atividades de endoglucanase (CMCase), 
determinada por meio da dosagem dos açúcares redutores produzidos na degradação enzimática da carboximetilcelulose, e os resultados de proteína bruta do extrato enzimático bruto, determinado pelo método de Bradford. Os resultados estão organizados em função da umidade em base seca (50\%, 60\% e 70\%) e para cada umidade em função da variação do tempo de fermentação (24h, 48h, $72 \mathrm{~h}$ e $96 \mathrm{~h}$ ) na temperatura de fermentação de $25^{\circ} \mathrm{C}$. Para cada tratamento foram quantificados a atividade enzimática e o teor de proteína bruta.

As endoglucanases são as enzimas responsáveis por iniciar a hidrólise da celulose. Essas enzimas atuam randomicamente na região amorfa da cadeia de celulose, clivando ligações $\beta-1,4$ da molécula e liberando como produto oligossacarídeos de diversos graus de polimerização (DIENES et al., 2004; MARTINS et al., 2008). A carboximetilcelulose (CMC) é utilizada como substrato preferencial para quantificar a atividade dessas enzimas (CAO; TAN, 2002; FARINAS et al., 2011).

\section{Discussão}

A sacarificação realizada durante o processo de fermentação em estado sólido consiste na conversão enzimática dos polissacarídeos em açúcares fermentáveis. A celulose é hidrolisada inicialmente pelas endoglucanases, que clivam aleatoriamente o polissacarídeo criando terminais livres para a atuação das exoglucanases. Essas enzimas atuam sobre as cadeias de celulose liberando glicoses e celobioses (BALAT et al., 2008).

Na Figura 1, observa-se que a variação da atividade específica enzimática ocorreu em função do tempo de fermentação e da umidade, à temperatura constante $\left(25^{\circ} \mathrm{C}\right)$. Observou-se que houve um acréscimo na atividade específica da enzima CMCase em função do tempo de fermentação, até que em 72 horas ocorreu sua maximização, com posterior redução dessa atividade.

A maior atividade específica enzimática pode ser explicada pela maior afinidade do fungo por baixos valores de umidade. Palacios-Cabrera et al. (2005) relatam que o crescimento de Aspergillus niger não é afetado por baixas umidades em temperaturas de 25 a $35{ }^{\circ} \mathrm{C}$. 0 aumento da atividade enzimática em função do tempo de fermentação pode ser explicado em
Tabela 1 - Efeito da variação da umidade e do tempo de fermentação sobre a atividade enzimática e o teor de proteína bruta produzidos durante a fermentação do resíduo de cajá à temperatura ambiente de $25^{\circ} \mathrm{C}$

\begin{tabular}{cccc}
\hline Umidade (\%) & Tempo (h) & $\begin{array}{c}\text { Atividade } \\
\text { enzimática } \\
\left(\mathbf{U} \cdot \mathbf{~ m L}^{-\mathbf{1}}\right)\end{array}$ & $\begin{array}{c}\text { Proteína } \\
\left(\mathbf{m g} \cdot \mathbf{~ m L}^{-\mathbf{1}}\right)\end{array}$ \\
\hline \multirow{2}{*}{50} & 24 & 0,635 & 0,016 \\
& 48 & 0,886 & 0,006 \\
& 72 & 3,186 & 0,006 \\
60 & 96 & 2,281 & 0,080 \\
& 24 & 0,626 & 0,061 \\
& 48 & 0,847 & 0,019 \\
& 72 & 2,888 & 0,016 \\
70 & 96 & 2,291 & 0,064 \\
& 24 & 0,578 & 0,012 \\
& 48 & 0,876 & 0,015 \\
& 72 & 1,781 & 0,016 \\
& 96 & 1,280 & 0,050 \\
\hline
\end{tabular}

Fonte: Dados da pesquisa.

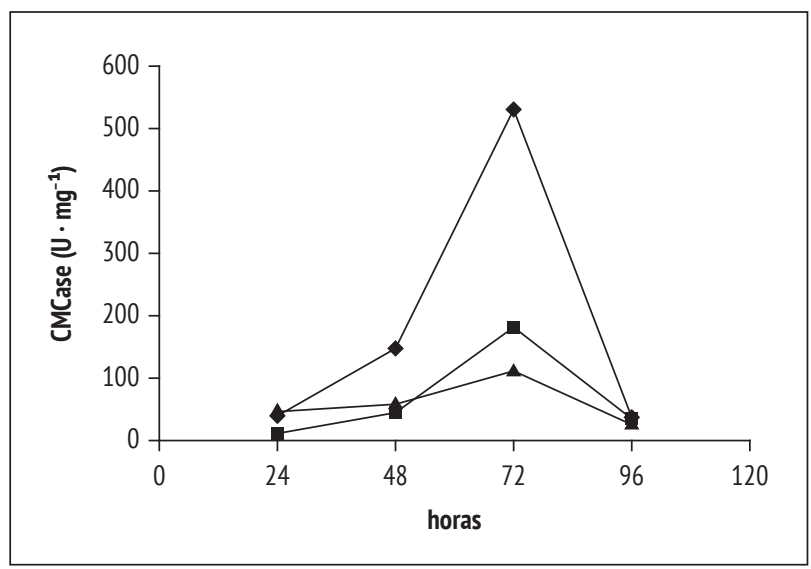

Figura 1 - Atividade específica de endoglucanase $\left(\mathrm{U} \cdot \mathrm{mg}^{-1}\right.$ de proteína) a $25^{\circ} \mathrm{C}$ em função do tempo de fermentação e da umidade (ロ) 50\%, (•) 60\% e (A) $70 \%$ em base seca

Fonte: Dados da pesquisa.

razão do aumento da disponibilidade de açúcares redutores da matéria-prima, necessários para o desenvolvimento do micro-organismo. Entre 24 e 72 horas de fermentação todos os tratamentos apresentaram 
elevação na atividade enzimática. Após esse período, todos os tratamentos demonstraram redução na produção de endoglucanase, fato possivelmente atribuído ao esgotamento de nutrientes, ou por acúmulo de produtos inibidores da síntese enzimática ou do crescimento celular. Os produtos finais de uma dada via metabólica são frequentemente inibidores das enzimas que catalisam os primeiros passos da via. Esse mecanismo é conhecido como feedback negativo ou autoalimentação (WHITAKER, 1994).

Biazus et al. (2006), trabalhando com malte de milho, observaram que a produção de enzima, a princípio, é lenta, acelerando posteriormente até alcançar seu valor máximo. A partir daí, a concentração de produtos gerados pelas enzimas faz com que parte destas seja inibida e sua atividade reduza a um valor constante, sendo também observado no presente trabalho (Figura 1).

0 teor de água ideal para o crescimento celular deve formar uma película de água na superficial, facilitando assim a dissolução e a transferência de nutrientes e oxigênio do meio para o micro-organismo. Entretanto, os espaços entre as partículas devem permanecer livres para permitir a difusão de oxigênio e a dissipação de calor (GERVAIS; MOLIN, 2003). Na Tabela 2, pode ser observado que a elevação no teor de água provoca a redução da atividade enzimática, esta pode estar relacionada com a inibição do fungo marcado pela extrapolação do nível de água ideal para o desenvolvimento da linhagem selecionada no caso de $50 \%$.

Omemu et al. (2005) obtiveram maior rendimento de hidrólise do amido de mandioca por Aspergillus niger após 72 horas de fermentação, concordando com Alva et al. (2007). 0 decréscimo na atividade da enzima com o aumento do tempo de incubação pode

Tabela 2 - Efeito da umidade sobre a atividade específica enzimática após 72 horas de fermentação a $25^{\circ} \mathrm{C}$

\begin{tabular}{|c|c|c|}
\hline $\begin{array}{l}\text { Umidade } \\
\qquad(\%)\end{array}$ & $\begin{array}{l}\text { Atividade específica } \\
\qquad\left(\mathrm{U} \cdot \mathrm{mg}^{-1}\right)\end{array}$ & $\begin{array}{c}\text { Redução } \\
\text { (\%) }\end{array}$ \\
\hline 50 & 531,00 & - \\
\hline 60 & 180,50 & 66,01 \\
\hline 70 & 111,31 & 79,03 \\
\hline
\end{tabular}

Fonte: Dados da pesquisa. se dar em razão da produção de coprodutos, resultante do metabolismo microbiano, além do esgotamento de nutrientes, inibindo o crescimento do fungo e a formação da enzima (GUPTA et al., 2010; SHAFIQUE et al., 2009).

O fungo utilizado mostrou ser eficaz na produção enzimática por fermentação, como mencionado por Pandey et al. (2000), os quais destacam que o Aspergillus é o micro-organismo mais usado na produção enzimática.

\section{Conclusões}

Em função dos dados levantados, pode-se concluir que o resíduo do cajá apresentou-se como uma excelente matéria-prima para a produção de endoglucanase por fermentação em estado sólido com o auxílio do micro-organismo Aspergillus niger. Após 72 horas de fermentação e com umidade de $50 \%$, base seca, a produção da enzima foi maximizada. 0 aumento no teor de água reduz significativamente a produção enzimática. 0 resíduo do cajá e água, em diferentes concentrações, foi suficiente para o fungo sintetizar a enzima, demonstrando assim que a enzima é constitutiva.

\section{Agradecimentos}

Os autores agradecem ao Conselho Nacional de Desenvolvimento Científico e Tecnológico (CNPq), pela bolsa de Iniciação Tecnológica Industrial (ITI) concedida, e ao Banco do Nordeste (BNB), pelo apoio financeiro concedido.

\section{Referências}

ABDESHAHIAN, P. et al. Solid substrate fermentation for cellulose production using palm kernel cake as a renewable lignocellulosic source in packed-bed bioreactor. Biotechnology and Bioprocess Engineering, Busan, v. 16, n. 2, p. 238-244, 2011.

ALVA, S. et al. Production and characterization of fungal amylase enzyme isolated from Aspergillus sp. JGI 12 in solid state culture. African Journal of Biotechnology, Nairobi, v. 6, n. 5, p. 576-581, 2007. 
BALAT, M.; BALAT, H.; OZ, C. Progress in bioethanol processing. Progress in Energy and Combustion Science, New York, v. 34, n. 5, p. 551-573, 2008.

BASSO, T. P.; GALLO, C. R.; BASSO, L. C. Atividade celulolítica de fungos isolados de bagaço de cana-de-açúcar e madeira em decomposição. Pesquisa Agropecuária Brasileira, Brasília, v. 45, n. 11, p. 1282-1289, 2010.

BIAZUS, J. P. M. et al. Otimização da secagem do malte de Zea mays. Ciência e Tecnologia de Alimentos, Campinas, v. 26, n. 4, p. 787-792, 2006.

BRADFORD, M. A rapid and sensitive method for the quantitation of microgram quantities of protein utilizing the principle of protein-dye binding. Analytical Biochemistry, New York, v. 72, n. 1/2, p. 248-254, 1976.

BRITO, H. R. Caracterização química de óleos essenciais de Spondias mombin L., Spondias purpúrea L. e Spondias sp (cajarana do sertão). 2010. 67 f. Dissertação (Mestrado em Ciências Florestais) - Centro de Saúde e Tecnologia Rural, Universidade Federal de Campina Grande, Campina Grande, 2010.

CAO, Y.; TAN, H. Effects of cellulase on the modification of cellulose. Carbohydrate Research, Bromsgrove, v. 337, n. 14, p. 1291-1296, 2002.

CASTRO, A. M.; PEREIRA, N. Produção, propriedades e aplicação de celulases na hidrólise de resíduos agroindustriais. Química Nova, São Paulo, v. 33, n. 1, p. 181-188, 2010.

COUTO, S. R.; SANROMÁN, M. A. Application of solid-state fermentation to food industry - A Review. Journal of Food Engineering, Califórnia, v. 76, n. 3, p. 291-302, 2006.

DIENES, D.; EGYHÁZI, A.; RÉCZEY, K. Treatment of recycled fiber with Trichoderma cellulases. Industrial Crops and Products, Tucson, v. 20, n. 1, p. 11-21, 2004.

FARINAS, C. S. et al. Evaluation of operational parameters on the precipitation of endoglucanase and xylanase produced by solid state fermentation of Aspergillus niger. Brazilian Journal of Chemical Engineering, v. 28, n. 1, p. 17-26, 2011.

GALEMBECK, F.; BARBOSA, C. A. S.; SOUSA, R. A. Aproveitamento sustentável de biomassa e de recursos naturais na inovação química. Química Nova, São Paulo, v. 32, n. 3, p. 571-581, 2009.

GERVAIS, P.; MOLIN, P. The role of water in solid-state fermentation. Biochemical Engineering Journal, Amsterdam, v. 13, n. 2/3, p. 85-101, 2003.
GUPTA, A.; GAUTAM, N.; MODI, D. R. Optimization of aamylase production from free and immobilized cells of Aspergillus niger. Journal of Biotechnology and Pharmaceutical Research, v. 1, n. 1, p. 1-8, 2010.

LAUFENBERG, G.; KUNZ, B.; NYSTROM, M. Transformation of vegetable waste into value added products: $(A)$ The upgrading concept; (B) Practical implementations. Bioresource Technology, New York, v. 87, n. 2, p. 167-198, 2003.

LEE, R. L. et al. Microbial cellulose utilization: fundamentals and biotechnology. Microbiology and Molecular Biology Reviews, Washington, v. 66, n. 5, p. 506-577, 2002.

MALIK, S. K. et al. Optimization of process parameters for the biosynthesis of cellulases by Trichoderma viride, Pakistan Journal of Botany, v. 42, n. 6, p. 4243-4251, 2010.

MANERA, A. P. et al. Utilização de resíduos agroindustriais em processo biotecnológico para produção de B-galactosidase de Kluyveromyces marxianus CCT 7082. Acta Scientiarum. Technology, Maringá, v. 33, n. 2, p. 155-161, 2011.

MARTINS, L. F. et al. Comparison of Penicillium echinulatum and Trichoderma reesei cellulases in relation to their activity against various cellulosic substrates. Bioresource Technology, New York, v. 99, n. 5, p. 1417-1424, 2008.

MILLER, G. L. Use of dinitrosalicylic acid reagent for determination of reducing sugar. Analytical Chemistry, Washington, v. 31, n. 3, p. 426-428, 1959.

MINAFRA, C. S. et al. Perfil bioquímico do soro de frangos de corte alimentados com dieta suplementada com alfa-amilase de Cryptococcys fravus e Aspergillus niger HM2030. Revista Brasileira de Zootecnia, Viçosa, v. 39, n. 12, p. 2691-2966, 2010.

OBEROI, H. S. et al. Production of cellulases through solid state fermentation using kinnow pulp as a major substrate. Food Bioprocess Technology, Dublin, v. 3, n. 4, p. 528-536, 2010.

OMEMU, A. M. et al. Hydrolysis of raw tuber starches by amylase of Aspergillus niger AM07 isolated from the soil. African Journal of Biotechnology, Nairobi, v. 4, n. 1, p. 19-25, 2005.

PALACIOS-CABRERA, H. et al. Growth of Aspergillus ochraceus, A. carbonarius and A. niger on culture media at different water activities and temperatures. Brazilian Journal Microbiology, São Paulo, v. 36, n. 1, p. 24-28, 2005. 
PANDEY, A.; SOCCOL, C. R.; MITCHELL, D. New developments in solid state fermentation: I-bioprocesses and products. Process Biochemistry, London, v. 35, n. 10, p. 11531169, 2000.

PELIZER, L. H.; PONTIERI, M. H.; MORAES, I. O. Utilização de resíduos agro-industriais em processos biotecnológicos como perspectiva de redução do impacto ambiental. Journal of Technology Management \& Innovation, Santiago, v. 2, n. 1, p. 118-127, 2007.

ROBINSON, T.; NIGAM, P. Bioreactor design for protein enrichment of agricultural residue by solid state fermentation. Biochemical Engineering Journal, Amsterdam, v. 13, n. 2/3, p. 197-203, 2003.

ROSSI, S. C. et al. Improving fruity aroma production by fungi in SSF using citric pulp. Food Research International, v. 42, p. 484-486, 2009.

SALES, M. R. et al. Variáveis que influenciam a produção de celulases e xilanases por espécie de Aspergillus. Pesquisa Agropecuária Brasileira, Brasília, v. 45, n. 11, p. 1290-1296, 2010.

SANTOS, D. T. et al. Potencialidades e aplicações da fermentação semi-sólida em biotecnologia. Janus, São Paulo, v. 3, n. 4, p. 165-183, 2006.
SANTOS, J. R. A.; GOUVEIA, E. R. Produção de bioetanol de bagaço de cana-de-açúcar. Revista Brasileira de Produtos Agroindustriais, Campina Grande, v. 11, n. 1, p. 27 33, 2009.

SHAFIQUE, S.; BAJWA, R.; SHAFIQUE, S. Screening of Aspergillus niger and A. flavus strains for extra cellular alphaamylase activity. Pakistan Journal of Botany, Pakistan, v. 41, n. 2, p. 897-905, 2009.

SOCCOL, C. R.; VANDENBERGHE, L. P. S. Overview of applied solid-state fermentation in Brazil. Biochemical Engineering Journal, Amsterdan, v. 13, n. 2/3, p. 205-218, 2003.

WHITAKER, J. R. Principles of enzymology for the food sciences. 2nd ed. New York: CRC Press, 1994.

Recebido: 28/02/2010 Received: 02/28/2010

Aprovado: 09/09/2011

Approved: 09/09/2011 